\title{
Notas sobre a formação socioespacial da Amazônia
}

Notes on the socio-spatial formation of the Amazon region

Raul da Silva Ventura Neto(1)

(1) Universidade Federal do Pará

\section{Abstract}

This article offers a review of the economic history of the Amazon region, focusing on the transformations in the local productive forces during moments of conflict between the local fractions of the capital, the labor force, and the Amazonian biome. The article mobilizes the concept of socio-spatial formation suggesting directions to overcome the limitations present in the Marxist critique offered by the critical geography scholarship about the role of space in the dialectic between productive forces, relations of production and the application of Fernand Braudel method of analysis. The article argues that the accumulation of learning about the management of the Amazonian biome inserted in a production structure primarily devoted to extractivism determined the paths available for the transformation of the elements of the regional productive forces. The article argues this deterministic process operates in a structural condition that continues shaping the possible routes for the development of Amazon region.

\section{Keywords}

socio-spatial formation of the Amazon region, colonial period of Amazon region, land use patterns.

JEL Codes R11, N96, R52.

\section{Resumo}

Este artigo oferece uma releitura da história econômica da Amazônia com foco nas transformações que ocorreram em elementos da força produtiva regional em momentos específicos de embate entre as frações locais do capital e da força de trabalho e o bioma amazônico. Recorre-se ao conceito de formação socioespacial, indicando caminhos para superar as limitações presentes na crítica marxista, a partir das contribuições da geografia crítica sobre o papel do espaço na dialética entre forças produtivas e relações de produção e do uso do método de análise histórica braudeliano. Toma-se como hipótese que os caminhos disponiveis para a transformação dos elementos da força produtiva regional foram determinados pelo acúmulo de aprendizado sobre o manejo do bioma amazônico ocorrido no interior de uma estrutura de produção prioritariamente dedicada ao extrativismo de coleta, mas em uma condição estrutural que exerce influência sobre os caminhos possiveis para o desenvolvimento da região amazônica.

\section{Palavras-chave}

formação socioespacial da Amazônia, Amazônia colonial, padrões de uso da terra.

Códigos JEL $R 11, N 96, R 52$. 


\section{Formação socioespacial: fundamentos teórico-meto- dológicos para uma análise empírica}

Descrever a Amazônia contemporânea é um desafio permanente de compreensão dos elementos que definem a sua formação econômica, social e espacial. Na forma de notas sobre a formação socioespacial da Amazônia, este artigo oferece uma releitura da história econômica regional com foco nas transformações que ocorreram em elementos da força produtiva regional em momentos específicos de embate entre as frações locais do capital e da força de trabalho e o bioma amazônico.

Para isso, recorre-se ao conceito de formação socioespacial, indicando caminhos para superar as limitações presentes na crítica marxista, particularmente as da primeira metade do século XX a respeito do conceito de formação econômica e social de Marx e Engels e das suas interpretações a partir do materialismo histórico enquanto método de análise da história. Por ser farto de definições ambígua e repletas de lacunas (Fiori, 2003), o materialismo histórico estimulou interpretações determinísticas sobre a dialética base-superestrutura de Marx e Engels, tornadas hegemônicas na história do marxismo no século XX, que prejudicaram o avanço teórico sobre o conceito de formação econômica e social (Aruto, 2015). Com destaca Habermas (1983), sem a pressão determinística, a teoria da história de Marx e Engels apenas defende que, do embate entre os homens em cooperação e a natureza, se estabelece um movimento dialético entre os elementos da força produtiva e as relações de produção capaz de reconfigurar continuamente a natureza daquele indivíduo e a superestrutura ideológica da sociedade em que está inserido.

Habermas (1983) entende que no interior de uma formação historicamente determinada se estabelecem formas de integração social, que separam os mecanismos de aprendizado entre o terreno do agir comunicativo e o terreno do agir instrumental; e princípios de organização em que, por meio do acúmulo de aprendizado que provém da interação entre o saber tecnicamente valorizável e a dimensão da consciência prático-moral, consolidam os caminhos disponíveis para que as relações de produção se adaptem às novas exigências da força produtiva, reorganizando os modos de produção possíveis a essa formação econômica e social.

De forma complementar, autores da crítica marxista da geografia defendem a inserção do espaço como mais uma instância entre as diversas 
esferas que compõem a totalidade social, colocando-se como categoria inseparável do conceito de formação econômica e social (Santos, 1978). Para Harvey (2013), o papel do espaço no materialismo histórico deve ser interpretado a partir de seis elementos conceituais ${ }^{1}$ que se vinculam e determinam mutuamente durante o processo material de produção de excedentes ao longo do tempo. As mudanças tecnológicas e as formas organizacionais do trabalho que dela decorrem desvelam a relação interiorizada que existe entre homem e natureza com base no processo de trabalho que este se encontra submetido, suas concepções mentais sobre o mundo e as relações sociais que este estabelece na sua vida cotidiana. Na visão de Lefebvre (1976) o espaço social deve ser interpretado como um componente central na dialética entre forças produtivas e relações sociais de produção, o locus da troca entre capital e trabalho em que se configuram relações socioespaciais de produção. Estas, por sua vez, tornam-se uma categoria analítica-chave para a interpretação de uma realidade concreta e historicamente determinada por meio do conceito de formação socioespacial.

Para interpretar uma realidade concreta e historicamente determinada é possível associar ao conceito de formação socioespacial a temporalidade e o método histórico-estrutural ${ }^{2}$ sugerido por Braudel (1972), elevando a ideia de estrutura - coerências que circunscrevem relações relativamente fixas entre realidades e massas sociais, que, ao tornarem-se elementos estáveis, comandam o escoamento da história - como elemento teórico fundamental para entender como frações do capital contornam contradições durante as fases de expansão e declínio de um ciclo econômico.

Neste artigo, os referenciais acionados servem para analisar um longo período em que o extrativismo de coleta ${ }^{3}$ mostrava-se como a atividade 1 Os seis elementos listados por Harvey são: a tecnologia, a relação com a natureza, o processo efetivo de produção, a produção e reprodução da vida cotidiana, as relações sociais e as concepções mentais.

2 A temporalidade de Braudel define uma divisão tripartite da noção de tempo, determinando um primeiro nível de tempo, o do ambiente (longue durée), estrutural, longo, imóvel e duradouro. Apresenta mudanças lentas, quase imperceptíveis, mas ainda assim existentes. Um segundo nível de tempo, da história social e cultura, é o tempo da conjuntura, tempo médio, caracterizado pela mudança e pelas oscilações cíclicas das civilizações. Por fim, o tempo de eventos (histoire événmentielle), aquele das superfícies e dos efeitos enganosos, nos quais repousam os acontecimentos próprios da vida cotidiana (Braudel, 1972). O método histórico-estrutural acompanha, em linhas gerais, tanto o estruturalismo latino-americano, consagrado na interpretação de raiz cepalina das economias do continente, quanto o materialismo histórico de Marx e Engels (Borja, 2013).

3 O termo "extrativismo de coleta" é definido por Costa (2010, p. 175) e designa uma prática de origem colonial de extração de excedentes comercializáveis na economia amazônica, por 
hegemônica e articuladora da formação socioespacial da Amazônia. Para isso, apresenta-se a ideia de estruturas de produção: um arranjo teórico que permite entender como, por meio dos conceitos de formas de integração social e princípios de organização, o acúmulo de aprendizado sobre o bioma amazônico permitiram ocorrências de renovações evolutivas sobre os elementos da força produtiva regional, garantindo resiliência ao processo de geração de mercadorias exportáveis a partir do extrativismo de coleta.

Nesse sentido, toma-se como hipótese que os caminhos disponíveis para a transformação dos elementos da força produtiva regional foram determinados pelo acúmulo de aprendizado sobre o manejo do bioma amazônico ocorridos no interior de uma estrutura de produção prioritariamente dedicada ao extrativismo de coleta. No auge da fase gomífera do ciclo extrativista, esse processo levaria à consolidação de um sistema de trocas comerciais informais, próprio da formação amazônica e conhecido como Sistema de Aviamento, cujos mecanismos de controle e dominação sobre força de trabalho do campesinato caboclo e do nordestino migrante tornou possível o atendimento da elevada demanda internacional por látex da seringueira durante mais de meio século.

\section{Gênese das estruturas de produção na Amazônia colonial e o lastro espacial para o Sistema de Avia- mento}

Por ter sido ocupada um século após as primeiras inserções portuguesas em território brasileiro, o projeto colonial para a Amazônia sofreu adaptações ao projeto consolidado de viabilização mercantil da colônia brasileira, já que as condições naturais do bioma inviabilizaram as técnicas agronômicas dominadas até então, levando a modificações nas estratégias de colonização consagradas na conquista ultramarina portuguesa (Costa, 2010). Com isso a conquista do território deu-se pela combinação de dois fatores cruciais: as condições do bioma, que possibilitavam a coleta em larga escala de mercadorias prontas para o comércio internacional; e a utilização

meio de sua coleta no interior da floresta, em que a efetividade do trabalho depende de um tipo de conhecimento que se pode classificar como tradicional, pelo qual a força de trabalho possui um domínio (cognitivo) do processo produtivo da natureza originária, sem demandar a anulação das propriedades originais do ecossistema. 
do trabalho qualificado das populações indígenas que, não só conheciam os ciclos naturais da floresta, como controlavam espaços de florestas "domesticadas" (Clement, 2010), sendo que ambos tornaram o conquistador europeu altamente dependente do conhecimento acumulado do indígena sobre a floresta (Costa, 2010).

Essa dependência do conhecimento acumulado do indígena sobre o espaço e a natureza da região tropical tornaria o processo de conquista daquele território fecundo para a constituição do que definimos como estrutura de produção extrativista, que se caracteriza pela hegemonia de relações socioespaciais de produção nas quais o uso do indígena como força de trabalho escrava levaria em conta, além da força física para o trabalho braçal, o sofisticado conhecimento dos povos nativos sobre os ciclos naturais da floresta e sobre o uso da natureza tropical de forma "domesticada", transformando esse milenar acúmulo de aprendizado em motor de acumulação para o sistema colonial de exploração (Clement, 2010; Heckenberger, 2013).

Nessa fase inicial, de gênese da formação Amazônia e das formas de integração entre saber tradicional e saber tecnicamente valorizável, a legislação indigenista foi a chave-mestra da política do Estado português durante o período colonial para assegurar a exploração (Mello, 2010). A partir delas foi possível a consolidação de relações socioespaciais de produção e princípios de organização por meio dos quais o trabalho qualificado do indígena, aldeado ou escravizado, podia ser apropriado às demandas do comércio internacional de especiarias tropicais.

A possibilidade de leis mais brandas no sentido do grau de exploração, somente possíveis pela interpretação que a igreja católica possuía do indígena (Mello, 2009), os segmentaria entre aliados, obtidos a partir de descimentos para aldeamentos missionários localizados na orla dos principais rios da região; e cativos e escravizados, tidos como inimigos que normalmente provinham das chamadas "guerras justas" (Farage, 1991). Pode-se inferir que, nas empreitadas de captura do indígena, o colono leigo incentivava ainda mais os descimentos já que, ao aldeado sob a tutela dos missionários, era garantida proteção contra os colonos leigos, dispensando a escravização forçada, mas à custa da condição de converter-se em um não índio no aldeamento (Hemming, 2009).

Por um lado, o modo de compulsão escravista da força de trabalho indígena, aos moldes do modelo de escravidão dos cativos africanos, sucumbe como relação de trabalho hegemônica tanto pela violência do pro- 
cesso de captura ${ }^{4}$ quanto pela impossibilidade de controle efetivo sobre a força de trabalho escravizada, devido à amplitude e complexidade das áreas de coleta (Costa, 2012). Por outro lado, os aldeamentos constituíam unidades quase autônomas de produção, misto de espaço de conversão e catequização, com espaço de moradia e de troca de mercadorias. ${ }^{5}$ Ao "descerem" das aldeias os índios morariam e trabalhariam na coleta extrativa das drogas do sertão para os agentes da colônia, tudo em troca de um salário irrisório, tornando-se um escravo disfarçado compulsoriamente de trabalhador livre.

$\mathrm{Na}$ fase de gênese das relações socioespaciais de produção dedicadas ao extrativismo de coleta, o aldeamento seria o espaço social melhor articulado à estrutura extrativista de produção. Nos aldeamentos as atividades cotidianas dos indígenas engendravam princípios de organização que definiram novas as relações socioespaciais de produção que, tanto se apropriavam do aprendizado acumulado a respeito da domesticação da floresta tropical e do manejo sobre seus recursos singulares (Clement, 2010; Heckenberger, 2013), quanto adequava o trabalho qualificado do indígena a novos usos do cotidiano do aldeamento.

De fato, o domínio sobre a produção de embarcações era essencial para que a mercadoria extraída nas áreas do aldeamento chegasse até a cidade de Belém. Isso provavelmente exigiu a interação entre as duas dimensões do saber: de um lado, o saber tecnicamente valorizável, calculável da engenharia naval portuguesa; e do outro lado a dimensão da consciência prático-moral do indígena, o aprendizado acumulado sobre as madeiras regionais, a floresta, os rios e a forma das canoas. O resultado dessa dialética são os ubás e igarités, canoas grandes responsáveis pelas viagens de coleta dos produtos do extrativismo, com capacidade para até 50 índios (Henrique; Morais, 2014), cujo manejo de fabricação e manutenção ficava restrito à força de trabalho indígena e cabocla.

$4 \bigcirc$ único caso em que a escravidão era permitida pela legislação indigenista portuguesa era para prisioneiros de investidas armadas contra aldeias, o que impulsionou constantes empreitadas militares em busca de força de trabalho durante grande parte do século XVII, ao custo de genocídios do indígena (Farage, 1991).

5 Eram três tipologias: o aldeamento missionário cujos índios estavam a serviço unicamente das ordens religiosas, cuja renda revertia livre de impostos para elas, como uma forma de pagamento pelo serviço de catequização; aldeamentos do serviço real, nos quais a força de trabalho indígena era utilizada estritamente para os serviços do Estado, incluso os serviços militares; e por último os aldeamentos de repartição, cuja força de trabalho indígena era utilizada para a subsistência dos moradores das vilas e cidades próximas. 
Em um contexto de conquista do território amazônico, a dependência do conhecimento das populações indígenas sobre manejo domesticado da floresta parece ter influenciado mesmo a localização dos assentamentos missionários e cidades. ${ }^{6}$ Estes, muitas vezes, foram assentados sobre antigas cidades indígenas, como é o caso da cidade de Santarém (Vicentini, 2004), ou mesmo em áreas de provável ação antrópica prévia em que existiam grandes concentrações de especiarias, como é o caso dos cravos na região do alto Xingu (Cardozo; Souza, 2008).

Em que pese o maior grau de controle sobre o extrativismo de coleta, e a consequente hegemonia sobre o comércio de especiarias, durante o primeiro século de ocupação, os colonos missionários elevaram-se à posição de classe dominante mais poderosa da colônia amazônica, aparentemente à revelia do Estado português (Mello, 2009).

Quando tem início a fase de exploração do cacau amazônico, principal especiaria extraída do bioma amazônico a partir de 1730 (Santos, 1980), a colônia amazônica apresenta um forte crescimento econômico, a uma taxa média anual de crescimento na ordem $6,3 \%$ a.a., cuja produtividade independia da expansão imediata da força de trabalho regional. Essa expansão foi motivada, sobretudo, pelo crescimento da produtividade do sistema em torno de 4,21\% a.a. A produção em tonelada exportada de drogas do sertão apresentou um ritmo de crescimento de 5,26\% a.a. e uma expansão produtiva que não parece apresentar uma correlação direta com o crescimento populacional, que apresentou taxas de aproximadamente $1 \%$ a.a (Costa, 2012).

O ritmo de crescimento, nas primeiras décadas do século XVIII, acirrou a disputa política entre colonos leigos e religiosos ${ }^{7}$ em torno do acesso à força de trabalho e ao conhecimento indígena sobre o bioma, numa conjuntura que combinava à renovação do Estado português mediada por Marquês de Pombal. Não por acaso, em 1753, o diagnóstico Pombalino sobre o desenvolvimento da colônia amazônica sugeria que os motivos para a suposta pobreza da região estavam relacionados à incapacidade das or-

$6 \mathrm{Em} \mathrm{1718,} \mathrm{eram} 51$ aldeamentos apenas no rio Amazonas, divididos entre as principais ordens religiosas: 19 aldeias da ordem dos Jesuítas, 15 dos capuchinhos, 12 de carmelitas e 5 de mercedários (Vicentini, 2004).

7 De fato, as querelas entre os colonos leigos e os missionários religiosos em torno da disputa pelo acesso ao indígena percorreram boa parte do século XVII e início do XVIII, sendo decidida pela Junta das Missões, que mantinha o Estado português relativamente neutro nas decisões (Mello, 2009). 
dens religiosas de qualificar o indígena para o trabalho, além de certa "perversão" dessas ordens pela riqueza obtida com o extrativismo de coleta.

A intervenção estatal ocorre no sentido do reposicionamento forçado das classes dominantes regionais, expulsando as ordens religiosas e confiscando seus ativos (Rezende, 2006), entre eles a força de trabalho aldeada que, somente sob o controle dos jesuítas era de aproximadamente 12 mil indígenas em 63 missões amazônicas (Schmink; Wood, 2012). As Reformas Pombalinas para a Amazônia pretendiam, finalmente, estruturar um projeto colonial de exploração baseado na monocultura e na força de trabalho do escravo africano, dessa vez por meio de fortes subsídios estatais, que, por fim, consolidaram o que se define no artigo como estrutura de produção agrícola. Nessa estrutura, diferente da estrutura extrativista, prevalece uma dialética interna em que as relações socioespaciais de produção são predominantemente baseadas nas relações de escravidão do africano, na dependência de privilégios mercantis mediados pelo Estado e na grande propriedade rural, a princípio voltada para atender o mercado externo em cultivos principalmente de arroz, café, algodão e cana de açúcar (Dias, 1970).

A Companhia Geral do Grão-Pará e Maranhão ${ }^{8}$ foi a principal instituição econômica criada no bojo das Reformas Pombalina para a Amazônia e tinha como missão o desenvolvimento da agricultura e o povoamento da região por meio de subsídios estatais para consolidação da agricultura de plantation. Visando assegurar a manutenção da unidade territorial da América portuguesa, as Reformas Pombalinas buscaram instituir um novo papel político para o nativo da região, apoiando a miscigenação com portugueses e proibindo o uso da língua geral (nheengatu) na colônia, medidas que apenas ampliaram a sua aculturação (Rezende, 2006).

A abolição da escravidão indígena principiaria com o Diretório dos Índios, organização civil da coroa e que tinha como pano de fundo ideológico que a liberdade plena dos índios precisava ser mediada pelo homem branco, sendo esse trabalho conduzido pelo Diretor, funcionário civil do Estado português responsável por conduzir o indígena aos costumes e às leis do Reino. Os diretores ascendem como verdadeiros tiranos no interior da floresta (Vicentini, 2004), detendo o controle sobre a força de trabalho

8 Instituída em 1755 e extinta em 1778, a Companhia Geral do Grão-Pará e Maranhão foi criada para fomentar o comércio ultramarino entre a metrópole portuguesa e o Grão-Pará, visando, sobretudo, a manutenção da soberania portuguesa sobre o território amazônico (Dias, 1970). 
aldeada e o poder sobre a política de descimentos, além da repartição dos indígenas entre outros colonos. Até o final do século XVIII, sob a égide do Diretório dos Índios, o aumento da destribalização e a miscigenação do indígena transformaria a população da Amazônia numa grande maioria de caboclos subjugados (Schmink; Wood, 2012).

Um programa de reordenamento político foi imposto ao espaço urbano amazônico, com a fundação de novos assentamentos, em áreas estratégicas do território, e a elevação de antigos aldeamentos missionários à categoria de vilas. As vilas pombalinas significavam a ocupação política do território revestida de prioridade sobre a ocupação física, incentivando a fixação dos caboclos e colonos ao solo das cidades e auxiliando no projeto de povoamento e manutenção do território sob o domínio do império português (Araújo, 2012). O mercado interno regional seria ampliado pelo crescimento da população das vilas com o aumento da migração ao longo do século XVIII, dando suporte à estrutura de produção como produtora de gêneros de subsistência, com destaque para o gado vacum cultivado nos campos do Marajó (desde os Jesuítas) e alguns engenhos de açúcar e aguardente na região do baixo Tocantins (Veloso, 1998).

Em grande medida isso significava que a produção não extrativa pouco influenciaria na pauta de exportação regional, concentrada basicamente em café e arroz, que não superava a exportação das especiarias florestais ligadas à estrutura extrativista, com o cacau representando a maior parte das exportações - $61 \%$ do total (Santos, 1980) - e sem haver provas de que a lavoura cacaueira tenha suplantado a pura atividade de extração do fruto (Furtado, 2007). Por sua vez, o crescimento econômico da colônia amazônica, nesse período, foi mais modesto, não ultrapassou a taxa de $2 \%$ a.a., com a produção crescendo a taxas de $2,99 \%$ a.a. (Costa, 2012). O domínio do Diretório dos índios encerrou-se dois anos antes da virada para o século XIX, num momento de forte expansão dos preços do cacau na economia mundial, entre 1790 e 1815,9 e de uma vantajosa queda das exportações venezuelanas em virtude de lutas internas pela independência.

O fim do controle dos diretores estimulou que os indígenas destribalizados abandonassem as vilas e se dispersassem pela região, constituindo com a população cabocla uma miríade de assentamentos ribeirinhos. A dispersão parece indicar que os aprendizados acumulados no interior 9 No porto de Belém, o preço por arroba do cacau passa de Rs. $1 \$ 000$ em 1789 para Rs. $3 \$ 100$ em 1805. 
das vilas não conduziram à capacitação do indígena ou do caboclo dentro da dimensão de um saber tecnicamente valorizável, dificultando ainda mais sua ascensão social como camadas médias de comerciantes e profissionais liberais. De fato, esse posto seria ocupado por outras categorias de imigrantes árabes e judeus, além de portugueses, que, atraídos pelos incentivos à colonização durante a gestão pombalina, chegaram à Amazônia no final do século XVIII e início do XIX (Benchimol, 1998).

Enquanto os migrantes europeus, árabes e judeus se estabeleciam nas principais cidades da rede urbana amazônica, o campesinato-caboclo da região se estabelecia em pequenos grupos familiares na beira dos rios (Vicentini, 2004). A dispersão da força de trabalho cabocla, ao longo dos rios, carregou relações socioespaciais de produção que se articulavam à estrutura extrativista, na qual a coleta e troca de artigos florestais servia para atender a demanda do caboclo por produtos manufaturados. Era agora a sujeição da força de trabalho cabocla e indígena às atividades de coleta que se apresentaria como elemento essencial para assegurar a reprodução do capital na formação amazônica. A continuidade nas formas de dominação sobre a força de trabalho indígena e cabocla e sobre o conhecimento acumulado acerca do manejo do bioma seria possibilitada pelo isolamento das unidades produtivas do campesinato caboclo e pela condição de um comércio de trocas desiguais, mediado por gêneros do extrativismo que serviam como equivalente geral da economia no isolamento do mundo rural amazônico. É nesse contexto que surge o Sistema de Aviamento - uma espécie de economia amazônica própria, como definiu Santos (1980) - como forma hegemônica de fazer negócios no mundo rural da formação amazônica.

O padrão ribeiro de ocupar o espaço amazônico acentuava a dependência do modal fluvial para o transporte de mercadorias e pessoas, possibilitando que algumas frações do capital comercial se especializassem na forma de comissários volantes, comerciantes do rio que mais tarde ficariam conhecidos como "regatões" (Schmink; Wood, 2012). Caracterizada como "um produto original da Amazônia" (Veríssimo, 1970), essa fração endógena do capital comercial local correspondia a um comerciante isolado que, uma vez abastecido de artigos manufaturados nas principais vilas da região, descia os rios em busca de produtos do extrativismo, utilizando esses artigos em trocas com ribeirinhos ou mesmo com tribos indígenas locais (Henrique; Morais, 2014; Mcgrath, 1999). 
O regatão personifica a evolução de um elemento central da força produtiva e um agente econômico fundamental na estrutura de produção extrativista da formação amazônica. A ideia do regatear vem da pechincha, do questionamento, da insistência para obter o preço mais baixo durante o processo de troca entre mercadoria, obtendo vantagens comerciais pelo convencimento ou coerção, condição típica da fração do capital comercial. Ademais, a escassez de moeda até praticamente o início do século XX tornava o comércio no mundo rural amazônico regulado por equivalentes gerais que assumiam a forma de diversos produtos: a cachaça, os fardos de algodão e a própria semente de cacau durante o século XVIII e boa parte do XIX. O dinheiro como meio circulante e equivalente geral só era realidade em algumas relações de comércio urbanas e nas atividades agrícolas voltadas para exportação (Santos, 1980), ambas inacessíveis ao mundo indígena e do caboclo, que desconheciam o preço final do que coletavam para a troca (Veloso, 1998).

A principal função do regatão seria a intermediação entre uma rede urbana esparsa e uma economia parcialmente monetizada com o mundo rural formado por uma infinidade de assentamentos ribeirinhos, conectando indiretamente a força de trabalho do campesinato-caboclo aos interesses do comerciante urbano, "patrão" do regatão enquanto este não saldasse as dívidas do aviamento.

O contexto de isolamento espacial e de longas viagens era fecundo para o estabelecimento do Sistema de Aviamento como um sistema de crédito totalmente informal e não monetizado, mas de extrema complexidade e capilaridade dentro do território amazônico. A partir do Aviamento a rede urbana dendrítica da região hierarquizou-se, consolidando cidades com funções diferenciadas, como Santarém e Manaus na região do Tapajós, Cametá na região do rio Tocantins, e Belém como capital regional (Corrêa, 1987).

O período colonial finda com a consolidação de duas estruturas de produção na formação socioespacial da Amazônia, cada uma delas representando relações socioespaciais distintas dentro do sistema. Uma extrativista utilizava a força de trabalho campesina-cabocla por meio de relações desiguais de troca com os regatões e pequenos e médios comerciantes urbanos que os aviavam, o que sustentava uma rede de troca e de empréstimos, o Sistema de Aviamento. Ainda que de menor importância sobre a pauta exportadora, havia uma segunda estrutura, de produção agropecuária, organizada por famílias fidalgas portuguesas que compunham a chamada 
elite colonial e, como tal, distinguiam-se pela propriedade de fazendas, cabeças de gado, escravos, engenhos e imóveis urbanos (Cancela, 2006). Observada nessa perspectiva, o riquíssimo ciclo de exportação do látex da seringueira, que virá em sequência, expõe tanto a potencialidade de crescimento e robustez da estrutura de produção extrativista, quanto seus limites mais evidentes.

\section{0 que a borracha desvela?}

A fase gomífera do ciclo extrativista é produto direto de reconfigurações do capital industrial internacional ocorridas na metade do século XIX, pelo qual o látex da seringueira amazônica (hevea brasiliensis) se tornou, em pouco tempo, um insumo básico de uma das mais pujantes indústrias do período (Santos, 1980). Com o advento da vulcanização, que permitia estabilizar a borracha em relação à variação de temperatura, ocorre uma mudança severa na demanda por esse produto, até então, nativo do bioma amazônico, ${ }^{10}$ obrigando a uma oferta mais sistemática de borracha no mercado internacional pelos agentes locais da estrutura extrativista.

Efetivamente, o primeiro registro oficial de exportação da borracha em bruto é de 1827. Contudo, até 1848, sete anos após a invenção da vulcanização, a borracha ainda estava longe de ser o gênero principal da pauta exportadora amazônica. ${ }^{11}$ Assim, durante as primeiras três décadas da fase gomífera do ciclo extrativista ainda se observam características típicas da fase anterior (Weinstein, 1993, p. 24). Ou seja, inúmeras unidades caboclas de produção ribeirinhas, uma miríade de comerciantes volantes e alguns pequenos e médios aviadores urbanos instalados nas principais cidades da rede urbana, onde também se encontravam as casas exportadoras. Do outro lado, havia grandes proprietários de terra, particularmente paraenses, já que a atividade agrícola pouco se desenvolveu na província do Amazonas

10 O látex amazônico já era exportado para países como Inglaterra e Estados Unidos há muitas décadas, juntamente com outros produtos do extrativismo de coleta, sendo um dos muitos produtos apresentados pela sociedade indígena aos portugueses durante o período colonial e classificado como droga do sertão. Ao longo de todo o período gomífero sua produção herdava do conhecimento tradicional indígena a forma de incisões na seringueira e de transformação do látex a partir de processos rudimentares de defumação com sementes de palmeira silvestre (Ouricuri, Inajá, babaçu etc.) (Santos, 1980, p. 42-44).

$114^{\circ}$ lugar em termos de valor exportado com 202:500 mil-réis. 
(Loureiro, 2007). Dedicavam-se às atividades monocultoras e justamente por isso se colocavam politicamente contrários à economia extrativista da borracha, sob o discurso de que essa prática simbolizava o atraso da região (Weinstein, 1993).

Pode-se dizer que por trás da negação da elite agrícola colonial à economia extrativista, havia uma real incapacidade de participar dos ganhos permitidos pela exportação gomífera por três gargalos centrais: a desarticulação com a força de trabalho do caboclo, a falta de poupança interna e o desconhecimento sobre a localização das áreas de maior ocorrência da hevea. A primeira dependeria da subsunção formal da força de trabalho cabocla, dificultada pela não monetarização das relações de troca e pelo fato de o campesinato-caboclo amazônico ser autônomo nas suas atividades de coleta, não podendo ser cerceado no seu acesso a terra e ao bioma amazônico. Ademais, a possibilidade de praticar o extrativismo em terras devolutas ou não reclamadas na Amazônia, onde havia seringais inexplorados, inviabilizava, naquele momento, qualquer tipo de cerceamento formal da propriedade fundiária, com vistas a constituir um mercado de trabalho baseado em relações capitalistas de produção.

Como é previsível, o emprego da força de trabalho escrava no extrativismo de coleta permanecia altamente arriscado para o proprietário, em especial no da borracha, em que as dimensões de uma "estrada" de seringa geralmente era na ordem dos quilômetros. ${ }^{12}$ Ademais, o acesso à força de trabalho escrava naquele momento específico - pós-lei Eusébio de Queirós - só podia contar com um limitado mercado interno de escravos, fortemente orientado para suprir o complexo econômico cafeeiro fluminense e, posteriormente, o paulista. O segundo ponto era a baixa oferta de capital disponível para investimento, basicamente imobilizado em propriedades rurais e urbanas, além de escravos. Estima-se que, até 1855, a renda interna anual da Amazônia estava situada entre 4 mil e 8 mil contos de réis. Uma dimensão exígua para dinamizar, de forma imediata, qualquer tipo de atividade econômica que permitisse o aumento da demanda por látex no mercado mundial (Santos, 1980).

O último ponto tem uma determinação eminentemente espacial, já que as principais propriedades da elite colonial não possuíam reservas extensas de seringueiras nas suas áreas de floresta. Sendo a hevea uma árvore nati12 Estrada de seringueiras era o modo como se organizava a área de colheita da seringa, possuía a forma de uma alça muito mal definida e podia conter de 100 a 200 árvores. 
va de áreas mais altas e secas da floresta, em especial nas bacias dos rios Madeira, Purus e Solimões, no Pará sua maior ocorrência era em regiões ainda pouco exploradas, como as bacias do Xingu e do Tapajós, ou então naquelas parcialmente exploradas, mas que os proprietários não tinham conhecimento da existência de seringais nativos, como na parte ocidental da região das ilhas do arquipélago do Marajó (Weinstein, 1993).

Nessa conjuntura de impossibilidades de migrar para atividades do extrativismo gomífero, o domínio sobre relações socioespaciais de produção da estrutura extrativista permaneceria concentrado nas formas de acesso à rede de comércio regional, mediado pelo Sistema de Aviamento e por relações desiguais de troca entre os aviadores, regatões e seringueiros. De forma gradual os comerciantes urbanos respondem à elevação no preço e à demanda da borracha no mercado externo orientando que os regatões trocassem suas mercadorias preferencialmente por borracha, impactando diretamente sobre as unidades produtivas dispersas do campesinato-caboclo, que passam a produzir, além do seu portfólio habitual, também látex (Costa, 2012).

A pressão externa ${ }^{13}$ tensionaria a dialética interna da estrutura extrativista, produzindo gargalos, produtivos e espaciais, que limitavam a ampliação da oferta de látex. O interesse internacional permitiria a injeção do capital necessário para viabilizar a expansão da rede de coleta com a entrada de novas casas exportadoras nas cidades de Belém e Manaus e sua participação como agentes do Sistema de Aviamento. Os gargalos referentes à força de trabalho seriam paulatinamente solucionados com a migração espontânea de nordestinos: quase 55 mil indivíduos nas primeiras três décadas do ciclo. Importa lembrar que a escassez de braços livres para o trabalho rural era um problema que também se apresentava a outros complexos econômicos brasileiros naquele momento, o que na Amazônia só seria efetivamente superado alguns anos mais tarde e sempre com braços nordestinos (Furtado, 2007). Num primeiro momento, esses migrantes inserem-se na dinâmica das trocas desiguais com os regatões e aviadores, contudo sua falta de conhecimento sobre o bioma amazônico os direciona para a produção ainda mais concentrada no látex, elevando a produtividade do sistema, que chega a mobilizar aproximadamente $13 \%$ da população da Amazônia em 1880 (Santos, 1980). apenas entre os anos de 1845 a 1851. 
Os gargalos espaciais ampliam-se conforme os seringueiros buscam novas áreas de coleta em direção à província do Amazonas, elevando a importância de Manaus dentro da rede urbana amazônica como segundo maior entreposto comercial de exportação da borracha (Corrêa, 1987). Esse movimento deriva em parte da própria forma predatória com que se extraía o látex, gerando um produto de menor qualidade que matava a árvore e forçava o deslocamento das estruturas produtivas ribeirinhas (Reis, 1957), aumentando a distância entre os seringais e os principais portos e inviabilizando, aos poucos, o sistema de transporte sob o comando dos regatões, ainda dependentes de barcos a vela. ${ }^{14}$

A nova escala de capital aviado exigiria redução no tempo de circulação entre os pontos de coleta e as casas exportadoras, priorizando estruturas de transportes mais velozes e com maior capacidade de carga. A liberação da bacia amazônica para a atuação de grandes companhias privadas de transporte fluvial de mercadorias e pessoas, utilizando barcos movidos a vapor, foi a solução do capital nacional e internacional, ambos subvencionados pelo Estado brasileiro (Gregório, 2010). Solução política que garantia não só a redução no tempo de circulação entre as cidades e os pontos de extração, como também a ampliação na quantidade de borracha transportada em uma só viagem ${ }^{15}$ (Loureiro, 2007).

A despeito da nova oferta de capital e das novas tecnologias de navegação, o maior ganho de produtividade viria da superexploração da força de trabalho nordestina no interior do seringal, criando um tipo híbrido de extrativista, especializado na extração do látex, mas desconhecedor de outras possibilidades de subsistência do bioma amazônico. Não por acaso a transumância do homem nordestino para a Amazônia coincidiu com o momento de maior exploração do látex (Furtado, 2007), de enriquecimento das elites locais do extrativismo e do fausto urbano das cidades de Belém e Manaus. A corrente migratória de 300 mil nordestinos (Benchimol, 2009, p. 154) deslocados para a região, entre 1877 e 1920, e que ocorreu num momento de transição das relações de produção no Brasil rumo ao trabalho assalariado, aconteceu sem promover modificações substanciais nas relações socioespaciais de produção do extrativismo de coleta, elevan-

14 Esses navios conseguiram reduzir o tempo de percurso de Manaus a Belém de 90 para apenas 22 dias, dobrando a capacidade de transporte (Loureiro, 2007).

15 Esses navios conseguiram reduzir o tempo de percurso de Manaus a Belém de 90 para apenas 22 dias, dobrando a capacidade de transporte (Loureiro, 2007). 
do extraordinariamente a produtividade do seringal.

Nas tentativas de escapar dos efeitos da seca ${ }^{16}$ e estimulados por uma massiva propaganda que vendia a ideia de enriquecimento fácil aos seringueiros, os cearenses, como eram tratados os nordestinos, fazem nascer uma nova Amazônia (Benchimol, 2009). O capital necessário para o traslado vinha principalmente de seringalistas ou de grandes casas aviadoras de Belém e Manaus, imprimindo ao migrante miserável uma dívida que deveria ser quitada com a extração da goma. A dívida do traslado se somaria a outras dívidas com o empório do seringal pela necessidade de adquirir alimentação e manufaturas para o trabalho na selva.

Para o seringalista, a condição de monopólio e monopsônio do barracão permitia manejar os preços dos gêneros alimentícios básicos (arroz, açúcar, farinha, café etc.) e das manufaturas, embutindo no preço vendido ao seringueiro uma altíssima margem de lucro que somava ao lucro dos outros agentes do Aviamento. Acontece que, assim como a borracha, os produtos vendidos no barracão também eram negociados pelo Aviamento, a casa importadora de Belém ou Manaus aviava os produtos para a casa aviadora, que em seguida poderia aviar para outros aviadores menores. Até chegar ao barracão esses produtos poderiam passar por até seis aviadores, atingindo preços exorbitantes e proporcionais à distância entre o seringal e a cidade, chegando a custar até 10 vezes mais que o seu valor na cidade (Santos, 1980).

Diferentemente das unidades autônomas ribeirinhas, os trabalhadores do seringal-empório ${ }^{17}$ eram proibidos de cultivar produtos de subsistência ou transacionar individualmente borracha com regatões, o que criou um tipo de estado policial dentro do seringal (Sarges, 2000). De fato, qualquer forma de comércio fora da intermediação do seringalista começaria a ser fortemente combatida, passando o regatão para a clandestinidade (Mcgrath, 1999), uma espécie de pirata fluvial que aos poucos revestiu-se de um sentimento antissemita e xenófobo pela predominância de árabes e judeus na atividade do regateio (Pinto, 1977).

16 Estima-se que entre 1877 e 1880 a estiagem no sertão nordestino tenha provocado a morte de 100 a 200 mil pessoas (Furtado, 2007).

17 "Seringal-empório eram empresas sob controle de frações locais (regionais) do capital mercantil, financiados por fontes internacionais, que controlavam centralmente diversas unidades de trabalhos isoladas - trabalhadores formalmente autônomos, não assalariados -, pelo monopólio da logística de suprimento e pelo monopsônio da compra do látex" (Costa, 2012 p. 68). 
O controle total sobre o tempo de trabalho do seringueiro era fundamental para atender à crescente demanda externa pelo látex, o que acabaria tornando-se o principal modo de assegurar o atendimento da demanda externa a partir do extrativismo e do aviamento. A superexploração da força de trabalho do seringueiro refletia tanto no seu curto tempo de vida, quanto no crescimento substancial da quantidade de borracha exportada da Amazônia brasileira, que foi multiplicada em cinco vezes entre 1881 e 1910 e saltou de oito mil toneladas para algo em torno de 34 mil toneladas. Em 1910, seu valor na praça de Belém ascendeu no período ao ritmo de $8,7 \%$ a.a. (Costa, 2012), chegando a representar $24 \%$ da exportação total do Brasil na virada do século XIX (Weinstein, 1993, p. 90).

O aumento de produtividade, nessa fase, promove a especialização das funções e hierarquização dos agentes do Sistema de Aviamento: o extrator do látex (seringueiro), o dono da terra e do empório (seringalista), comerciante de produtos manufaturados e gêneros alimentícios (aviador) e os donos do capital (casas exportadoras e bancos) necessário para viabilizar a safra e dar início à coleta do látex. São mudanças que ampliam a contradição entre rural e urbano na formação socioespacial da Amazônia: Belém e Manaus tornaram-se locus das casas exportadoras, casas aviadoras e bancos, enquanto no mundo rural espalhavam-se seringueiros nordestinos esmagados pelo peso de dívidas impagáveis.

O crescimento no número de casas aviadoras é expressivo nesse período, apenas no Pará passaram de 18 casas em 1880 para um total de 42 em 1890, sem ocorrer uma diminuição no capital subscrito da firma aviadora, raramente inferior a 100 contos de crédito inicial (Weinstein, 1993). Por sua vez, os bancos regionais se especializaram em empréstimos de curto prazo, capitalizando casas aviadoras, durante o período de safra do látex, por meio de notas promissórias a serem descontadas no momento de chegada da borracha na cidade (Leandro, 2015). A baixa capitalização desses bancos, com nenhum banco apresentando capital superior a 5 mil contos de réis, tornava-se um grave problema na medida em que os aviadores endividados ficavam sujeitos aos preços definidos pelas casas exportadoras, precisando vender a borracha assim que ela chegasse a Belém, sem ter como estocar o produto e barganhar preços melhores com os exportadores (Weinstein, 1993).

A exploração gomífera também reflete no crescimento das finanças estaduais e municipais, que são fortemente direcionadas para investimentos 
em infraestrutura urbana, mais a peso de endividamento do que de arrecadação (Sarges, 2000), o que remodela as principais capitais da região a toque de caixa. $\mathrm{O}$ ar europeizado dessas cidades vendia a ilusão do fausto necessário para estimular a vinda dos migrantes, urbanizando a região em patamares nunca antes vistos, o que elevou a demanda de gêneros agrícolas de primeira necessidade e a dependência de exportações, em que pese a especialização da força de trabalho rural direcionada à coleta do látex.

A demanda por alimentos de primeira necessidade é o que subsidia políticas de colonização de imigrantes estrangeiros para algumas áreas do território amazônico, sendo o projeto de maior envergadura o da colonização dirigida de europeus associada à expansão da Estrada de Ferro Belém-Bragança, num projeto de mais de 200 quilômetros de extensão que rasgava a floresta na região nordeste do Pará (Penteado, 1967). Nesses casos, diferentemente dos migrantes nordestinos, o Estado subvencionava a passagem e concedia um lote de 25 hectares de terras, assistência técnica e médica. Contudo, a péssima infraestrutura das colônias, além da falta de critério na seleção dos colonos por parte dos intermediários, fez com que boa parte deles abandonasse os lotes, posteriormente ocupados por nordestinos que conseguiam se libertar dos seringais (Emmi, 2013).

O contexto de aumento da migração urbana, crescimento econômico e de adoção de políticas de renovação da infraestrutura da cidade estimularam o surgimento de novas camadas sociais urbanas, formadas principalmente por profissionais liberais, trabalhadores da indústria e do comércio. Ao que parece, esses grupos sociais garantiam demanda efetiva para investimentos industriais voltados à produção local de bens de consumo não duráveis, consolidando uma estrutura de produção urbano-industrial, ainda mais periférica em relação à estrutura extrativista, mas que se caracteriza pela prevalência de relações capitalistas de produção pautadas no trabalho assalariado em espaços urbanos, prioritariamente concentrados nas cidades de Belém e Manaus.

Se por um lado as capitais industrializavam-se, renovavam infraestrutura e se expandiam, por outro, a necessidade de garantir os empréstimos para ativar o Sistema de Aviamento alçou a terra urbana dessas cidades à condição de principal capital fixo e reserva de valor das classes dominantes da formação amazônica (Weinstein, 1993). Pode-se dizer que os imóveis urbanos absorviam a maior parte do lucro gerado com a exportação do látex em virtude dos elevados aluguéis praticados na cidade (Cancela, 2006), 
possivelmente suplantando os ganhos no negócio com a borracha em tempos de baixa de preços.

Os imóveis eram garantidores de mais de $60 \%$ das hipotecas registradas em bancos regionais, o que configura o maior índice entre as regiões brasileiras, mesmo que essas hipotecas não passassem de 6,6\% da dívida hipotecária total do país (Leandro, 2015). Nos dados registrados em Belém nota-se que a quase totalidade das hipotecas deu como garantia imóveis urbanos, cerca de $86,5 \%$ dos contratos com hipotecas cujo prazo usual era de um ano, com juros de $12 \%$ em média (Leandro, 2015). As altas taxas de juros e o prazo curto dos empréstimos hipotecários, acompanhando a safra de extração do látex, tornavam os imóveis urbanos uma reserva de valor altamente volátil e associada ao desempenho do valor das exportações. Na medida em que eram usadas como garantia pode-se imaginar que expectativas altistas no preço da borracha conduziriam à compra de mais imóveis pelos aviadores, o que, provavelmente, também imprimia uma tendência altista de valorização do preço e dos aluguéis dos imóveis, formatando o mercado imobiliário das cidades de Belém e Manaus como um circuito secundário de reprodução do capital em relação à economia extrativista do látex (Ventura Neto, 2017).

Quando a violenta crise se mostra irreversível a partir de 1913, o que era reserva de valor mostra o seu valor real, aquele que era possível alcançar dentro de uma formação socioespacial cujos fundamentos eram o aviamento, o extrativismo de coleta e a baixa monetização das relações de produção. No auge do período já era público e notório o interesse do capital internacional em se libertar dos limites de produtividade da extração da borracha silvestre, assim como dos altos preços praticados pelos exportadores no mercado internacional. Também era de conhecimento da elite regional o financiamento extensivo em pesquisa durante mais duas décadas a partir do governo inglês, visando à obtenção de mudas de hevea, resistentes à monocultura, que seriam desenvolvidos nos protetorados britânicos do sudeste asiático.

Ao ser organizada a primeira empresa inglesa destinada à monocultura da seringa, cuja escala de produção conseguiu reduzir significativamente o preço do látex no mercado internacional, a queda no preço da borracha se deu com o aumento da oferta internacional o que inviabilizava estratégias de sustentação do preço da borracha pelo governo federal, como passou a 
defender a elite política regional (Weinstein, 1993). ${ }^{18}$ Com o aumento da oferta no mercado mundial e o declínio do preço internacional para patamares de anteriores a 1870, a crise inviabiliza completamente a estrutura do seringal-empório, impactando diretamente na renda interna regional, que retomou a patamares estimados para o ano de 1850 (Santos, 1980).

A crise incidiu sobre todos os agentes da economia e as finanças dos estados. Apesar de não terem sido registradas grandes falências entre bancos locais, somente uma forte diminuição dos seus capitais, pela metade do que eram no auge do ciclo, a praça de Belém registrou a falência de 47 casas aviadoras, totalizando um prejuízo de quase 67 mil contos de réis (Benchimol, 1999). Como era de se esperar, a crise do sistema produtivo foi seguida de uma extensa crise imobiliária que abalou as práticas rentistas da elite gomífera, que tinham no imóvel urbano a sua principal reserva de valor. Os imóveis, ao se tornarem propriedade dos bancos locais como pagamento pelas hipotecas, chegavam a ser colocados para leilão repetidas vezes para saldar as dívidas (Cancela, 2006), o que eliminou o componente especulativo do seu preço. Exemplo disso é que, em 1915, a cidade de Belém chegaria a possuir cerca de três mil casas vagas, enquanto em Manaus, na mesma época, esse número chegava a duas mil casas vagas, de um total de oito mil casas existentes (Benchimol, 1999).

Entretanto, é preciso dizer que algumas frações mais progressistas da elite gomífera tinham clareza quanto à irracionalidade do extrativismo gomífero e do Sistema de Aviamento (Reis, 1957). A elite da goma, particularmente os aviadores, fração da classe dominante local que provavelmente detinha a maior reserva de capital do sistema e os mais aptos para viabilizar investimentos de longo prazo, encontrava-se num contexto de incerteza estrutural no qual investimentos em heveicultura, antes de tudo, significavam a desmobilização de um capital fixado a terra na forma de imóveis urbanos. Além disso, o possível ganho de produtividade permitido pelo desenvolvimento da heveicultura dependeria da implantação do enfraquecimento do aviamento, do qual provinha a maior parte dos ganhos desses agentes.

Sem perspectivas de recuperação da economia regional a partir do comércio da goma, uma expressiva parcela da elite migrou para outros es-

18 De fato, o governo federal, através do Banco do Brasil, chega a comprar cerca de $1 / 4$ do total de borracha produzido em 1910, mas logo se desfaz quando percebe que os preços não mostravam sinais de recuperação (Weinstein, 1993, p. 245). 
tados ou refluiu para seus estados de origem. Não permaneceram para assistir a um limitado processo de substituição de importações em escala regional, baseada no aumento da demanda de bens de consumo pela população local que levou ao aumento das atividades industriais do parque de Belém (Costa, 2012). Os trabalhadores que, porventura, optaram por permanecer nos seringais passaram a substituir a atividade gomífera por pequenas lavouras de gêneros alimentícios de primeira necessidade, já que até mesmo os miseráveis custos de reprodução do seringueiro tornaram-se inviáveis para os seringalistas (Costa, 2012). A estes restou utilizar o patrimônio que possuíam, no caso as estradas de seringueiras, como pagamento para quitar dívidas com aviadores de Belém e Manaus, isso quando encontravam compradores (Cancela, 2006).

A forma como os elementos da força produtiva regional reorganizaram-se no sentido da próxima fase do ciclo extrativista, a partir de 1920 com a exploração da castanha-do-pará, evidencia a resiliência da estrutura de produção extrativista e sua hegemonia na formação amazônica. Uma condição que perdura até meados dos anos de 1960, quando ocorre o aprofundamento de políticas desenvolvimentistas, pelas quais o extrativismo de coleta e o Sistema de Aviamento seriam fortemente combatidos no meio de uma intrigante disputa intraelites do bloco de poder regional (Fernandes, 2010) que, ao final, penderia a favor de um ideário desenvolvimentista que paulatinamente desarticularia a hegemonia do aviamento, com suas elites de aviadores, importadores e regatões (Ventura Neto, 2017).

\section{Considerações finais e 0 que apontam as estruturas do tempo ao longo da formação amazônica}

Se por estrutura é possível interpretar uma realidade que o tempo veicula em longa duração e cuja estabilidade a faz comandar escoamento da história, como nos fala Braudel (1972), as estruturas do tempo longo da formação socioespacial da Amazônia parecem não só apontar para o extrativismo como atividade econômica preponderante, como também lançam luz sobre os comportamentos estruturais das estratégias de exploração e de uso do território pela classe dominante regional. À luz da história, estratégias de acumulação que parecem inerentes à elite da formação amazônica - a opção recorrente pelo rentismo fundiário e a apropriação das 
riquezas do território a partir da superexploração da força de trabalho e do conhecimento acumulado sobre o manejo do bioma - tornam-se, ao mesmo tempo, sustentáculo para a manutenção do status quo e obstáculo ao pleno desenvolvimento da região.

No período analisado neste trabalho, a preponderância do extrativismo de coleta condicionou transformações nas relações socioespaciais de produção e nos elementos da força produtiva regional que culminaram no Sistema de Aviamento, na especialização das unidades de coleta ribeirinhas e, no auge da exploração gomífera, na formação de um circuito secundário de valorização do capital nas cidades de Belém e Manaus. A despeito dos efeitos perversos, ainda se tratava de um padrão de extrativismo que precisava respeitar os ciclos naturais do bioma, o que resultava na prevalência de boa parte da floresta como espaço comum, já que o cerceamento da força de trabalho dependia do isolamento espacial e da subordinação por endividamento e, com base nisso, da continuidade de relações desiguais de troca.

A partir dos anos de 1970, quando a Amazônia se torna alvo e palco de um processo de radicalização conservadora das políticas desenvolvimentistas do governo militar, são introduzidas mudanças drásticas no espaço regional. Tais mudanças tanto desmontam a hegemonia da estrutura de produção extrativista e deslocam o extrativismo de coleta do posto de articulador da formação socioespacial da Amazônia, quanto introduzem dinâmicas socioespaciais e institucionais que modificam e reduzem o papel e a importância da cobertura florestal no funcionamento da economia da região. Não por acaso, é justamente a partir dos anos de 1970 que o desmatamento cresce acentuadamente. Em projeções recentes constata-se que o crescimento das áreas de lavoura, pasto e floresta plantada acontece em razão da área de floresta natural, como resultado do maior aumento da remuneração do pasto em relação à remuneração dos demais usos da terra (Carvalho; Domingues, 2016).

Ao mesmo tempo, a promessa desenvolvimentista para a região modificar as expectativas de investimento e lucratividade dos agentes econômicos faz ampliar a tendência de as cidades se comportarem como espaços de reinvestimento de excedentes, capitaneadas pelo papel ativo das elites locais em torno de estratégias rentistas com a propriedade imobiliária urbana.

Situada na periferia de um capitalismo que caminha desde os anos de 1970 para o protagonismo do capital financeiro, a Amazônia contemporânea reafirma o extrativismo - agora de aniquilamento - como atividade 
econômica preponderante. Esse extrativismo articula-se a um arranjo institucional que aprofunda a superexploração sobre a força de trabalho, rural e urbana e viabiliza novos modos de mercantilização dos conhecimentos seculares sobre o manejo do bioma. Nesse contexto, a reprodução da riqueza segue baseada em formas dependentes de estratégias de acumulação primitiva sobre o território, renovando e ampliando perdas e ameaças à floresta tropical, ao bioma amazônico e às populações da região.

\section{Referências}

ARAUJO, R. M. A urbanização da Amazônia e do Mato Grosso no século XVIII povoações civis, decorosas e úteis para o bem comum da coroa e dos povos. Anais do Museu Paulista: História e Cultura Material, v. 20, n. 1, p. 41-76, 2012.

ARUTO, P. C. A formação socioespacial dependente a partir da superexploração da força de trabalho: uma abordagem metodológica. 2015. 119 p. Dissertação (Mestrado) - Universidade Estadual de Campinas, Instituto de Economia, Campinas, 2015.

BENCHIMOL, S. Amazônia: formação social e cultural. Manaus: Editora Valer, 2009.

BENCHIMOL, S. Eretz Amazônia: os judeus na Amazônia. Manaus: Editora Valer, 1998.

BORJA, B. A formação da Teoria do Subdesenvolvimento de Celso Furtado. 2013. 393 f. Tese (Doutorado) - Instituto de Economia, Universidade Federal do Rio de Janeiro (UFRJ), Rio de Janeiro, 2013.

BRAUDEL, F. História e ciências sociais. Lisboa: Editora Presença, 1972.

CANCELA, C. D. Casamento e relações familiares na economia da borracha (Belém-1870-1920). Tese (Doutorado) - Universidade de São Paulo, 2006.

CARDOZO, A.; SOUZA, C. M. (Org.). Histórias do Xingu: fronteiras, espaços e territorialidades. Belém: EDUFPA, 2008.

CARVALHO, T. S.; DOMINGUES, E. P. Projeção de um cenário econômico e de desmatamento para a Amazônia Legal brasileira entre 2006 e 2030. Nova Economia, v. 26, n. 2, 22 dez. 2016.

CLEMENT, C. R. et al. Origin and domestication of native Amazonian crops. Diversity, v. 2, n. 1, p. 72-106, 2010.

CORRÊA, R. A periodização da rede urbana da Amazônia. Revista Brasileira de Geografia, v. 4, n. 3, p. 39-68, 1987.

COSTA, F. de A. Formação rural extrativista na Amazônia: os desafios do desenvolvimento capitalista (1720-1970). Belém: NAEA, 2012.

COSTA, F. de A. Lugar e significado da gestão pombalina na economia do Grão-Pará. Nova Economia, v. 20, n. 1, p. 167-206, 2010.

DIAS, M. N. A Companhia Geral do Grão-Pará e Maranhão. Belém: EDUFPA, 1970. 
EMMI, M. F. Um século de imigrações internacionais na Amazônia brasileira (1850-1950). Belém: Editora do Núcleo de Altos Estudos Amazônicos da UFPA, 2013.

FARAGE, N. As muralhas dos sertões: os povos indígenas no rio Branco e a colonização. Rio de Janeiro: Paz e Terra, 1991.

FERNANDES, D. A. A questão regional e a formação do discurso desenvolvimentista na Amazônia Tese (Doutorado) - NAEA, Universidade Federal do Pará (UFPA), 2010. (não publicada)

FIORI, J. L. O voo da coruja: para reler o desenvolvimentismo brasileiro. Rio de Janeiro: Record, 2003.

FURTADO, C. A formação econômica do Brasil. São Paulo: Companhia das Letras, 2007.

GREGÓRIO, V. M. O progresso a vapor: navegação e desenvolvimento na Amazônia do século XIX. Nova Economia, v. 19, n. 1, p. 185-212, 2010.

HABERMAS, J. Para a reconstrução do materialismo histórico. São Paulo: Brasiliense, 1983.

HARVEY, D. Para entender o capital. São Paulo: Boitempo, 2013.

HECKENBERGER, M. Tropical garden cities: Archaeology and memory in the Southern Amazon. Revista Cadernos do Ceom, v. 26, n. 38, p. 185-207, 2013.

HEMMING, J. Fronteira amazônica: a derrota dos índios brasileiros. São Paulo: Edusp, 2009.

HENRIQUE, M. C.; MORAIS, L. T. Estradas líquidas, comércio sólido: índios e regatões na Amazônia (século XIX). Revista de História, n. 171, p. 49-82, 2014.

LEANDRO, L. M. L. Crédito hipotecário no Brasil: uma análise comparativa entre as praças de Belém e São Paulo (1870-1930). 2015. 205 f. Tese (Doutorado) - Núcleo de Altos Estudos Amazônicos da Universidade Federal do Pará, Belém, 2015.

LEFEBVRE, H. The survival of capitalism: Reproduction of the relations of production. London: Allison \& Busby. 1976.

LOUREIRO, A. J. S. O Amazonas na época imperial. Manaus: Editora Valer, 2007.

MCGRATH, D. G. Parceiros no crime: o regatão e a resistência cabocla na Amazônia tradicional. Novos Cadernos NAEA, v. 2, n. 2, p. 57-72, 1999.

MELLO, M. E. A. S. Fé e Império: as juntas das missões nas conquistas portuguesas. Manaus: EDUFAM, 2009.

MELLO, M. E. A. S. O regimento das missões: poder e negociação na Amazônia portuguesa. CLIO: Revista de Pesquisa Histórica, n. 27.1, 2010.

PENTEADO, A. R. Problemas de colonização e de uso da terra na região Bragantina do estado do Pará. 1967. Tese (Doutorado) - Universidade de São Paulo, São Paulo, 1967.

PINTO, L. F. Amazônia (o Anteato da destruição). Belém: Grafisa, 1977.

REIS, A. C. F. A Amazônia que os portugueses revelaram. Ministério da Educação e Cultura, Serviço de Documentação, 1957.

REZENDE, T. V. F. A conquista e a ocupação da Amazônia brasileira no periodo colonial: a definição das fronteiras. 2006. Tese (Doutorado) - Universidade de São Paulo, 2006.

SANTOS, M. Sociedade e espaço: formação espacial como teoria e como método. Boletim Paulista de Geografia, São Paulo, n. 54, 1978. 
SANTOS, R. História econômica da Amazônia: 1800-1920. São Paulo: T. A Queiroz, 1980.

SARGES, M. Belém: riquezas produzindo a Belle-Époque (1870-1912). Belém: Paka-Tatu, 2000.

SCHMINK, M.; WOOD, C. H. Conflitos sociais e a formação da Amazônia. Belém: Ed. UFPA, 2012.

VELOSO, E. C. A. Estruturas de apropriação de riqueza em Belém do Grão-Pará, através do recenseamento de 1778. In: ACEVEDO, R. (Org.) A escrita da história paraense. Belém: NAEA/UFPA, 1998.

VENTURA NETO, R. A (trans)formação socioespacial da Amazônia: floresta, rentismo e periferia.

- Tese (Doutorado) - Instituto de Economia da Unicamp, Campinas, 2017.

VERÍSSIMO, J. Estudos amazônicos. Belém: UFPA, 1970.

VICENTINI, Y. Cidade e história na Amazônia. Curitiba: Editora UFPR, 2004.

WEINSTEIN, B. A borracha na Amazônia: expansão e decadência (1850-1920). São Paulo: Hucitec/Edusp, 1993.

\section{Sobre o autor}

Raulda Silva Ventura Neto - raulvneto@ufpa.br

Universidade Federal do Pará, Belém, Pará, Brasil.

ORCID: https://orcid.org/0000-0001-7124-1002.

\section{Sobre 0 artigo}

Recebido em 02 de outubro de 2018. Aprovado em 11 de março de 2019. 